\title{
Comparative Study on Effectiveness and Safety of Atorvastatin with Rosuvastatin in Hyperlipidemic Patients at a Tertiary Care Hospital in Nepal
}

\author{
Binod Raut ${ }^{1}$, Nimesh Paudel ${ }^{2}$, Deepti Shrestha ${ }^{3}$, Anant Bhosekar ${ }^{1}$ \\ 'Department of Pharmacology, Kathmandu Medical College and Teaching Hospital, Duwakot, Bhaktapur, Nepal, \\ 2Department of Internal Medicine, Kathmandu Medical College and Teaching Hospital, Sinamangal, Kathmandu, \\ Nepal, ${ }^{3}$ Department of Pharmacology, Nepal Medical College and Teaching Hospital, Jorpati, Kathmandu, Nepal
}

\section{Corresponding author:}

Binod Raut, BDS, MD

Department of Pharmacology, Kathmandu Medical College and Teaching Hospital, Duwakot, Bhaktapur, Nepal Email: binod14raut@gmail.com

Submitted : Oct 14, 2020

Accepted : Dec 2, 2020

\begin{abstract}
\section{Introduction}

Hyperlipidemia is one of the most contributing factors to coronary heart diseases. Statins have become standard medicine in clinical practice to reduce total cholesterol, low density lipoprotein and to increase high density lipoprotein cholesterol. This study is conducted to compare the effectiveness and safety of atorvastatin with rosuvastatin in hyperlipidemic patients.
\end{abstract}

\section{Methods}

This is a prospective observational study involving 150 patients conducted in the Department of Internal Medicine of Kathmandu Medical College and Teaching Hospital from July 2019 to March 2020. Patients newly diagnosed with hyperlipidemia were enrolled. Patients that were prescribed with $10 \mathrm{mg}$ of atorvastatin and $5 \mathrm{mg}$ of rosuvastatin by the treating physician once daily for 6 weeks were divided into two groups. Data was recorded in the customized proforma and the SPSS package version 20 was used for analysis.

\section{Results}

Patients that were prescribed with atorvastatin were put in group I and those prescribed with rosuvastatin were included in group II with 75 participants in each group. The mean age of the patients were 50.56 \pm 10.08 years in group I and $52.45 \pm 10.20$ years in group II with male to female ratio of 3:1. The mean BMI of group I was $25.36 \pm 1.74$ and that of group II was $26.48 \pm 2.21$ before therapy. There was a significant main effect of duration $\left(F_{1,74}=401.02, p<0.001\right)$ on the TG and TC levels $\left(F_{1.74}=1134.23, p<0.001\right)$ as well as $\left(F_{1,74}=614.99, p<0.001\right)$ on the LDL and HDL levels $\left(F_{1,74}=146.38, p<0.001\right)$.

\section{Conclusion}

Rosuvastatin was significantly more effective than atorvastatin in reducing levels of TG, TC and LDL-C. Rosuvastatin also significantly increased the level of HDL.

\section{Keywords}

Atorvastatin, hyperlipidemia, rosuvastatin 


\section{INTRODUCTION}

$(2$ ardiovascular diseases are the most common causes of morbidity and mortality in underdeveloped and developing countries and have direct impact in terms of health resources and loss of productivity. ${ }^{1}$ Hyperlipidemia or dyslipidemia is one of the most contributing factors to coronary heart diseases. It has major role in causing atherosclerosis and atherosclerosis associated conditions, such as coronary heart disease (CHD), ischemic cerebrovascular disease and peripheral vascular disease. ${ }^{2}$

Study conducted in Nepal revealed that 56\% of the population had dyslipidemia which accounts for $17 \%$ with elevated level of total cholesterol, $27 \%$ with raised triglyceride, $30 \%$ with decreased high density lipoprotein and $10 \%$ with raised low density lipoprotein. ${ }^{3}$

Many studies have established relationship between the raised level of total cholesterol (TC), and low density lipoprotein cholesterol (LDL-C) in the occurrence of coronary heart disease. In order to prevent occurrence of coronary heart disease the levels of TC and LDL-C should be reduced below $442.86 \mathrm{mg} / \mathrm{dl}$ and $116 \mathrm{mg} / \mathrm{dl}$, respectively. ${ }^{4,5}$ Statins have become standard therapeutic medicine in clinical practice to reduce total cholesterol and low density lipoprotein to prevent cardiovascular diseases. $^{6}$

They possess other important properties besides cholesterol lowering agents like antioxidant, antiinflammatory effects and antithrombotic effects, they also improve the endothelial activities and reduce the growth of atherosclerotic plaques. ${ }^{7}$ Statins have another important properties besides lowering of low density lipoprotein cholesterol (LDL-C) and triglycerides; it also contributes in the increment of high density lipoprotein cholesterol (HDL-C) which is also known as beneficial cholesterol in preventing coronary heart diseases. ${ }^{8}$
The aim of this study is to compare the effectiveness and safety of lipid lowering agent atorvastatin and rosuvastatin in hyperlipidemic patients in order to prevent from the coronary heart diseases in tertiary care hospital.

\section{METHODS}

This prospective observational study involving 150 patients based on convenience sampling was conducted in the Department of Internal Medicine of Kathmandu Medical College Teaching Hospital from July 2019 to March 2020 after obtaining ethical approval from Institutional Ethical Committee. The study recruited patients that attended the outpatient of Internal Medicine Department and were diagnosed with dyslipidemia with any of the following - TC>200mg/dl, serum triglycerides (TGs)>150mg/dL, low density lipoprotein cholesterol (LDL-C) > 100mg/dL, and high density lipoprotein cholesterol (HDL-C) $<40 \mathrm{mg} / \mathrm{dL}$ levels. Height and weight were also recorded for $\mathrm{BMI}$ scale and obesity. Before initiating the therapy, the baseline data of all patients were collected including lipid parameters with TC, TG, LDL-C an HDL-C (Table 1).

Patients that were prescribed $10 \mathrm{mg}$ atorvastatin once daily were included in group I and the patients that were prescribed with $5 \mathrm{mg}$ of rosuvastatin once daily were included in group II. Patients were followed up after 6 weeks for assessment of lipid profile. Results were recorded and compared from the baseline at the start of the drug therapy. Safety and tolerability were evaluated throughout the study on the basis of reported adverse effects. At the end of 6 weeks, data related to lipid profile, compliance and side effects were recorded.

Data were recorded in the customized proforma from the patient record sheets and reports during the outpatient follow up after taking written consent from the patient. SPSS package version 20 was used for statistical analysis.

Table 1. Baseline characteristics of the study groups

\begin{tabular}{lcc}
\hline \multicolumn{1}{c}{ Characteristics } & $\begin{array}{c}\text { Group I } \\
\text { (Atorvastatin 10 mg) }\end{array}$ & $\begin{array}{c}\text { Group II } \\
\text { (Rosuvastatin 5 mg) }\end{array}$ \\
\hline Number of patients & 75 & 75 \\
Age range (years) & 34 to 72 & 28 to 72 \\
Mean age (Years) & $50.56 \pm 10.08$ & $52.45 \pm 10.20$ \\
Sex (Male/Female) & $59 / 16(3: 1)$ & $55 / 20(3: 1)$ \\
Body mass index (BMI) & $25.36 \pm 1.74$ & $26.48 \pm 2.21$ \\
Lipid profile & & \\
Triglyceride (TG) (mg\%) & $241.83 \pm 32.13$ & $256.73 \pm 51.60$ \\
Total cholesterol (TC) (mg \%) & $254.55 \pm 24.38$ & $270.27 \pm 21.06$ \\
Low density lipoprotein (LDL) (mg \%) & $149.39 \pm 17.17$ & $165.25 \pm 13.85$ \\
High density lipoprotein (HDL) (mg \%) & $39.05 \pm 2.19$ & $39.39 \pm 1.89$ \\
\hline
\end{tabular}




\section{RESULTS}

The total number of patients included was 150 , with 75 in group I that prescribed with Atorvastatin and 75 in group II that were prescribed with Rosuvastatin. The age range of the patient was from 28 years to 72 years with mean age $50.56 \pm 10.08$ with male is to female ratio were 3:1 in group I and the age range was 28 to 72 years with $52.45 \pm 10.20$ years with male is to female ratio of $3: 1$ in group II. The mean body mass index (BMI) of group I was $25.36 \pm 1.74$ $\mathrm{kg} / \mathrm{m}^{2}$ and that of group II was $26.48 \pm 2.21 \mathrm{~kg} /$ $\mathrm{m}^{2}$ before drug therapy. Mean level of TG were $241.83 \pm 32.13$ and $256.73 \pm 51.60$. Similarly the level of TC, were $254.55 \pm 24.38$ and $270.27 \pm 21.06$, level of LDL were $149.39 \pm 17.17$ and $165.25 \pm 13.85$ and the level of HDL were $39.05 \pm 2.193$ and $39.39 \pm 1.89$ respectively in group I and group II before drug therapy (Table 1).

In group I the BMI of patients were change from $25.36 \pm 1.74$ to $24.64 \pm 1.96$ and the BMI of patients in group II were changed from $26.48 \pm 2.21$ to $26.55 \pm 2.21$. Similarly the level of TG in group I were reduced from $241.83 \pm 32.13$ to $212.60 \pm 30.33$ in group I and from $256.73 \pm 51.60$ to $193.64 \pm 36.75$ in group II.

The level of TC was reduced from $254.23 \pm 24.38$ to $224.97 \pm 21.40$ in group I and from $270.27 \pm 21.06$ to $212.19 \pm 18.15$ in group II. The level of LDL was reduced from $149.39 \pm 17.17$ to $136.81 \pm 18.97$ in group I and from $165.25 \pm 13.85$ to $122.63 \pm 12.25$ in group II. There was slight increase in the level of $\mathrm{HDL}$, from $39.05 \pm 2.19$ to $39.63 \pm 1.95$ in group I and from $39.39 \pm 1.89$ to $41.37 \pm 1.45$ in group II after drug therapy.

There was significant variation between the group I and group || after drug therapy with respect to $T G, T C, L D L$ and $H D L$ along with the test within subject's effects.

There was a significant main effect of duration $\left(F_{1,74}=401.02, p<0.001\right)$ on the TG levels. The effect of drug choice on TG levels was not significantly different $\left(F_{1,74}=2.90, p<0.93\right)$ which is not significant. Interaction between duration and drug choice has significant effect on TG levels $\left(F_{1,74}=10.20, p<0.002\right)$.

There was a significant main effect of duration $\left(F_{1,74}=1134.23, p<0.001\right)$ on the TC levels, however the effect of drug choice on TC levels was not significantly different $\left(F_{1,74}=0.33, \quad p<0.57\right)$. Interaction between duration and drug choice also had a significant effect on the TC levels $\left(F_{1,74}=172.27\right.$, $\mathrm{p}<0.001$ ).

There was a significant main effect of duration $\left(F_{1,74}=614.99, p<0.001\right)$ on the LDL levels, however the effect of drug choice on LDL levels was not significantly different $\left(F_{1,74}=0.13, p<0.71\right)$. Interaction between duration and drug choice also had a significant effect on the LDL levels
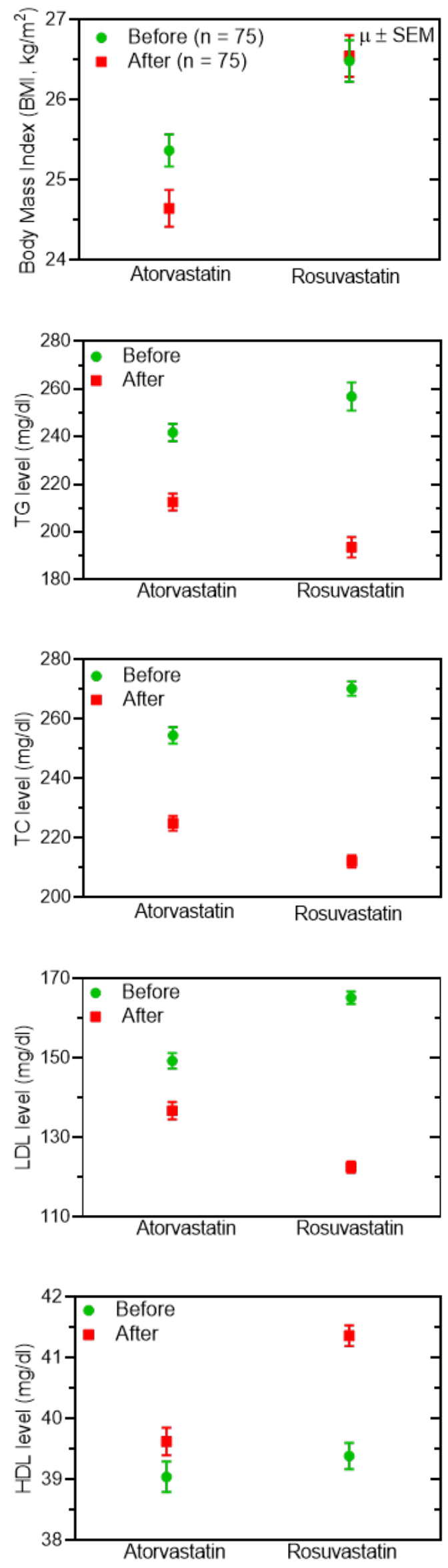

Fig 1. Changes in $B M I, T G, T C, L D L$ and $H D L$ after 6 weeks of drug therapy 
Table 2. Adverse effects in the study groups

\begin{tabular}{lcc}
\hline Adverse effects & $\begin{array}{c}\text { Group I } \\
\text { (Atorvastatin } \\
10 \mathbf{~ m g )}\end{array}$ & $\begin{array}{c}\text { Group II } \\
\text { (Rosuvastatin } \\
\mathbf{5} \mathbf{~ m g )}\end{array}$ \\
\hline Headache & $10(13.3 \%)$ & $4(5.3 \%)$ \\
Allergy & $6(8 \%)$ & $3(4 \%)$ \\
Gastritis & $8(10.6 \%)$ & $7(9 \%)$ \\
Insomnia & $5(6.6 \%)$ & $3(4 \%)$ \\
Fatigue & $12(16 \%)$ & $6(8 \%)$ \\
$\quad$ Total occurrence & $54.66 \%$ & $30.66 \%$ \\
\hline
\end{tabular}

$\left(F_{1,74}=266.44, p<0.001\right)$.

There was a significant main effect of duration $\left(F_{1,74}=146.38, p<0.001\right)$ on the HDL levels, the effect of drug choice on HDL levels was significantly different $\left(F_{1,74}=15.93, p<0.001\right)$. Interaction between duration and drug choice also had a significant effect on the HDL levels $\left(F_{1.74}=60.85, p<0.001\right)$.

Occurrence of adverse effects in atorvastatin (group I) was $54.66 \%$ while that in rosuvastatin (group II) was $30.66 \%$, of which the most common adverse effects were fatigue, headache, gastritis, allergic rashes and insomnia (Table 2).

\section{DISCUSSION}

In the present prospective, comparative 6 week follow up observational study in dyslipidemic patients using two regimens of Atorvastatin 10 $\mathrm{mg}$ once daily in group I and Rosuvastatin $5 \mathrm{mg}$ once daily in group II, we found that both the regimens were effective in improving the various parameters of lipid profile. When we compared the two regimens to determine the superiority of one therapy regime over the other; rosuvastatin has better effect with respect to Total cholesterol, LDL-C and $\mathrm{HDL}-\mathrm{C}$.

The age range of the patient was from 28 years to 72 years with mean age $50.56 \pm 10.08$ with male is to female ratio were $3: 1$ in group I and the age range was 28 to 72 years with mean age of $52.45 \pm 10.20$ years with male is to female ratio of $3: 1$ in group II which is similar with the prevalent age and also represent the sex distribution in study conducted in Nepal ${ }^{9}$ which suggest that on the increasing age and in male sex the prevalence of dyslipidemia is high due to decrease physical activity and uncontrolled dietary habits. The mean body mass index (BMI) of group I was $25.36 \pm 1.74 \mathrm{~kg} / \mathrm{m}^{2}$ that of group II was $26.48 \pm 2.21 \mathrm{~kg} / \mathrm{m}^{2}$ before drug therapy which is similar with the prevalence of obesity in Nepalese population ${ }^{10}$ the reason could be due to the enrollment of the maximum patients of urban region.

The level of TG in group I were reduced from $241.83 \pm 32.13 \mathrm{mg} / \mathrm{dl}$ to $212.60 \pm 30.33 \mathrm{mg} / \mathrm{dl}$ and from $256.73 \pm 51.60 \mathrm{mg} / \mathrm{dl}$ to $193.64 \pm 36.75 \mathrm{mg} / \mathrm{dl}$ in group II which was $12 \%$ and $24.60 \%$ respectively indicates that the patient under rosuvastatin therapy have reduced more TG compare to atorvastatin similar study concluded that triglyceride levels were reduced by a (median reduction -33.0\% on atorvastatin and $-27.6 \%$ on rosuvastatin. ${ }^{11}$ the reason could be the better metabolism of cholesterol by rosuvastatina with its long half life. Another study found reduction of TGs by $15.2 \%$ $(p<0.001)$, with the use of rosuvastatin. ${ }^{12}$ Similarly the level of TC was reduced from $254.23 \pm 24.38 \mathrm{mg} /$ dl to $224.97 \pm 21.40 \mathrm{mg} / \mathrm{dl}$ in group I and from $270.27 \pm 21.06 \mathrm{mg} / \mathrm{dl}$ to $212.19 \pm 18.15 \mathrm{mg} / \mathrm{dl}$ in group II after drug therapy which is $11.8 \%$ and $21.48 \%$ respectively which resemble with another similar study where TC levels were reduced by $35.1 \%$ ( $p<$ 0.001). ${ }^{12}$

The level of LDL-C was reduced from $149.39 \pm 17.17$ to $136.81 \pm 18.97$ in group I and from $165.25 \pm 13.85$ to $122.63 \pm 12.25$ in group II which is $8.7 \%$ and $26 \%$ respectively in another study it was found that LDL cholesterol was reduced by more than $50 \%$ versus baseline by both statins ${ }^{13}$ similarly in another study with the use of rosuvastatin it was found that the mean low density lipoprotein cholesterol (LDL-C) level decreased significantly from $108.9 \pm$ 16.5 to $91.6 \pm 24.5 \mathrm{mg} / \mathrm{dL}(\mathrm{p}<0.001)$ there was significant reduction which resembles with our finding. ${ }^{14}$ Another study found LDL-C by $48.5 \%$ ( $p<$ $0.001),{ }^{12}$ In the LUNAR study, while the atorvastatin $80 \mathrm{mg}$ provided a $42 \%$ reduction in LDL-C levels, rosuvastatin $40 \mathrm{mg}$ provided a $46.8 \%$ reduction in LDL-C levels at the end of 6 weeks. ${ }^{15}$ One of the review study on atorvastatin has concluded that based on dose range of 10 to $80 \mathrm{mg} / \mathrm{dl}$ has found that the reduction of LDL-C was by $37.1 \%$ to $51.7 \%$ which is quite high compared to our study the possible reason behind this decrease was due to inhibition of (HMG-COA ) reductase by one third to one half of the dose range and LDL-C is only one of the important biochemical product produced by HMG-COA reductase pathway and same study also resembles our finding which states that having similar dose response effect of both atorvastatin and rosuvasttin, atorvastatin is atleastthree fold less potent than rosuvastain in reducing total and LDLcholesterol. ${ }^{16}$ Similarly another study conducted by Marias et al. ${ }^{17}$ also concluded with $19 \%$ reduction of LDL-C with the use of rosuvastatin , Teramota et al ${ }^{18}$ concluded $42-52 \%$ reduction in LDL-C with the use of rosuvastatin, the difference was significantly higher compare to our study which could be due to difference in the variation of patient profile as well as dietary intake, social and cultural variation.

In this study, there was slight increase in the level of $\mathrm{HDL}$ which was $39.05 \pm 2.19 \mathrm{mg} / \mathrm{dl}$ to $39.63 \pm 1.95$ $\mathrm{mg} / \mathrm{dl}$ in atorvastatin group I and from $39.39 \pm 1.89$ $\mathrm{mg} / \mathrm{dl}$ to $41.37 \pm 1.45 \mathrm{mg} / \mathrm{dl}$ in rosuvastatin group 
II which was similar with another study in which both do not show significant increase in HDL level it was increased by small fold which was $4.1 \%$ in case of atorvastatin and $7.3 \%$ with rosuvastatin. Rosuvastatin has been approved for use at doses of $5-40 \mathrm{mg}$ to improve HDL and other parameters in dyslipidemic patients. 19,20 Study conducted by Farnier et al. ${ }^{21}$ also concluded that there was only $3 \%$ increament in HDL level with the use of rosuvastatin for weeks which resembles our study ,similarly Marias et al. ${ }^{17}$ also showed an increment of $5 \%$ with the use of Rosuvastatin for six weeks. Juszczyket al. ${ }^{22}$ showed improvements of $11 \%$ with the use of Rosuvastatin.this finding suggest that there was no significant in increament of HDL levels.

There was a significant main effect of duration $\left(F_{174}=401.02, p<0.001\right)$ on the TG levels. The effect of drug choice on TG levels was not significantly difference $\left(F_{1,74}=2.90, p<0.93\right)$ which is not significant. Interaction between duration and drug choice has significant effect on TG levels $\left(F_{1,74}=10.20, \quad p<0.002\right)$. similarly another similar study found that the level of TG decreased within both groups, but this decrease was not statistically significant [from $116.00(87.00-182.00) \mathrm{mg} / \mathrm{dL}$ to $110.00(89.00-154.00) \mathrm{mg} / \mathrm{dL}$ in the atorvastatin group; $p=0.532$, and from 154.50 (125.75-215.75) $\mathrm{mg} / \mathrm{dL}$ to $135.00(91.00-182.50) \mathrm{mg} / \mathrm{dL}$ in the rosuvastatin group, $p=0.052$, respectively. ${ }^{15}$ in contrast with our finding they concluded the level of significance with TGs by $15.2 \%(p<0.001)$, with the use of rosuvastatin. ${ }^{12}$ There was a significant main effect of duration $\left(F_{1,74}=1134.23, p<0.001\right)$ on the TC levels, however the effect of drug choice on TC levels was not significantly different ( $F 1,74=0.33$, $\mathrm{p}<0.57)$. Interaction between duration and drug choice also had a significant effect on the TC levels ( $F 1,74=172.27, p<0.001)$ in patients in another study also it was found significant effects in respect to TC (from $181.64 \pm 35.42 \mathrm{mg} / \mathrm{dL}$ to $138.36 \pm 34.08$ $\mathrm{mg} / \mathrm{dL}$ in the atorvastatin group, $\mathrm{p}<0.001$, and from $206.33 \pm 36.00 \mathrm{mg} / \mathrm{dL}$ to $143.27 \pm 39.95 \mathrm{mg} / \mathrm{dL}$ in the rosuvastatin group, $p<0.001$, respectively. ${ }^{23}$

There was a significant main effect of duration (F1, $74=614.99, p<0.001)$ on the LDL levels, however the effect of drug choice on LDL levels was not significantly different $(F 1,74=0.13, p<0.71)$. Interaction between duration and drug choice also had a significant effect on the LDL levels (F1, 74 $=266.44, p<0.001)$. Another study concluded with similar finding where LDL-C (from 120.08 \pm 27.68 $\mathrm{mg} / \mathrm{dL}$ to $72.22 \pm 25.09 \mathrm{mg} / \mathrm{dL}$ in the atorvastatin group, $p<0.001$, and from $131.69 \pm 24.61 \mathrm{mg} / \mathrm{dL}$ to $69.06 \pm 26.62 \mathrm{mg} / \mathrm{dL}$ in the rosuvastatin group, $p<0.001$, respectively were significantly reduced within atorvastatin and rosuvastatin. ${ }^{23}$ In similar study it was found that both atorvastatin and rosuvastatin were effective in reducing LDL-C level after 6 weeks of treatment but in comparison to both of them rosuvastatin was more effective than atorvastatin $(p<0.001) .{ }^{24}$ There was a significant main effect of duration ( $F 1,74=146.38, p<0.001$ ) on the HDL levels, the effect of drug choice on HDL levels was significantly different (F1, $74=15.93$, $p<0.001)$. Interaction between duration and drug choice also had a significant effect on the HDL levels ( $F 1,74=60.85, p<0.001)$. In similar study it was found rosuvastatin was more effective than atorvastatin in increasing level of HDL $(p \leq 0.002) .{ }^{24}$ The effect of rosuvastatin on $\mathrm{HDL}, 7.3 \%(95 \% \mathrm{Cl}$ 7.1 to 7.6$)$ is significantly greater than the effect of atorvastatin on $\mathrm{HDL}, 4.1 \%(95 \% \mathrm{Cl} 3.9$ to 4.2$) .{ }^{25}$ Based on reported adverse effects in comparison to both group of drugs common adverse effects were fatigue, headache, gastritis, allergic and insomnia in which the incidence was less in rosuvastatin group than atorvastatin group with $30.66 \%$ and $54.66 \%$ respectively. Similar study also concluded with the experience of adverse effects likemyopathy, myalgia, rhabdomyolysis, abdominal pain and headache. ${ }^{26}$ So considering the results with minimum adverse effects the drug reflects safe.

\section{CONCLUSION}

This study demonstrated that rosuvastatin $5 \mathrm{mg}$ is significantly more effective than atorvastatin $10 \mathrm{mg}$ in reducing TC, TG, LDL-C levels. It also significantly increases the level of HDL. The reported adverse effects are also lesser with rosuvastatin, so it can be considered safe and effective in dyslipidemic patients.

\section{CONFLICT OF INTEREST}

None declared.

\section{REFERENCES}

1. Ismail J, Jafar TH, Jafary FH et al. Risk factors for non-fatal myocardial infarction in young South Asian adults. Heart. 2004 Mar 1;90(3):259-63.

2. Papageorgiou N, Tousoulis $D$, Antoniades $C$ et al. The impact of statin administration in acute coronary syndromes. Hellenic J Cardiol. 2010 May 1;51(3):250-61.

3. Kumar AK, Suresh M, Sushhama N etal. The burden and determinants of non communicable diseases risk factors in Nepal: findings from a nationwide STEPS Survey. PLOSONE.2015;10(8):e0134834.

4. Lloyd-Jones DM, Larson MG, Beiser $A$ et al. Lifetime risk of developing coronary heart disease. The Lancet. 1999 Jan 9;353(9147):89-92

5. Trialists CT. Efficacy and safety of more intensive lowering of $L D L$ cholesterol: a meta-analysis of data from 170000 participants in 26 randomised trials. The Lancet. 2010 Nov 13;376(9753):167081.

6. Catapano AL, Reiner Ž, De Backer $G$ et al. ESC/EAS Guidelines for the management of dyslipidaemias: the Task Force for the management of dyslipidaemias of the European Society of Cardiology (ESC) and the European Atherosclerosis Society (EAS). Atherosclerosis. $2011 \mathrm{Jul}$ 1;217:1-44. 
7. Tsiara S, Elisaf M, Mikhailidis DP. Early vascular benefits of statin therapy. Current medical research and opinion. 2003 Jan 1;19(6):540-56.

8. Yood MU, McCarthy BD, Kempf J et al. Racial differences in reaching target low-density lipoprotein goal among individuals treated with prescription statin therapy. American heart journal. 2006 Oct 1;152(4):777-84.

9. Pokharel DR, Khadka D, Sigdel $M$ et al. Prevalence and pattern of dyslipidemia in Nepalese individuals with type 2 diabetes. BMC research notes. 2017 Dec 1;10(1):146.

10. Vaidya A, Shakya S, Krettek A. Obesity prevalence in Nepal: public health challenges in a low-income nation during an alarming worldwide trend. International journal of environmental research and public health. 2010 Jun; 7(6):2726-44.

11. Otokozawa S, Ai M, Van Himbergen T et al. Effects of intensive atorvastatin and rosuvastatin treatment on apolipoprotein B-48 and remnant lipoprotein cholesterol levels. Atherosclerosis. 2009 Jul 1;205(1):197-201.

12. Kostapanos MS, Milionis HJ, Filippatos TD et al. A 12-week, prospective, open-label analysis of the effect of rosuvastatin on triglyceride-rich lipoprotein metabolism in patients with primary dyslipidemia. Clinical therapeutics. 2007 Jul 1;29(7):1403-14.

13. Mihaylova B, Emberson J, Blackwell $L$ et al. The effects of lowering LDL cholesterol with statin therapy in people at low risk of vascular disease: meta-analysis of individual data from 27 randomised trials.

14. Thongtang N, Ai M, Otokozawa $S$ et al. Effects of maximal atorvastatin and rosuvastatin treatment on markers of glucose homeostasis and inflammation. The American journal of cardiology. 2011 Feb 1;107(3):387-92.

15. Pitt B, Loscalzo J, Monyak J et al. Comparison of lipid-modifying efficacy of rosuvastatin versus atorvastatin in patients with acute coronary syndrome (from the LUNAR study). The American journal of cardiology. 2012 May 1;109(9):1239-46.

16. Adams SP, Tsang M, Wright JM. Atorvastatin for lowering lipids. Cochrane Database of Systematic Reviews. 2015(3).
17. Marais AD, Raal FJ, Stein EA et al. A dose-titration and comparative study of rosuvastatin and atorvastatin in patients with homozygous familial hypercholesterolaemia. Atherosclerosis. 2008 Mar 1;197(1):400-6.

18. Teramoto T, Watkins C. Review of efficacy of rosuvastatin $5 \mathrm{mg}$. International journal of clinical practice. 2005 Jan;59(1):92-101.

19. Bullano MF, Kamat $S$, Wertz DA et al. Effectiveness of rosuvastatin versus atorvastatin in reducing lipid levels and achieving lowdensity-lipoprotein cholesterol goals in a usual care setting. American journal of health-system pharmacy. 2007 Feb 1;64(3):276-84.

20. Backes JM, Venero CV, Gibson CA et al. Effectiveness and tolerability of every-other-day rosuvastatin dosing in patients with prior statin intolerance. Annals of Pharmacotherapy. 2008 Mar;42(3):341-6.

21. Viigimaa $M$, Vaverkova $H$, Farnier $M$ et al. Ezetimibe/ simvastatin 10/20 mg versus rosuvastatin $10 \mathrm{mg}$ in high-risk hypercholesterolemic patients stratified by prior statin treatment potency. Lipids in health and disease. 2010 Dec 1;9(1):127.

22. Juszczyk MA, Seip RL, Thompson PD. Decreasing LDL cholesterol and medication cost with every-other-day statin therapy. Preventive cardiology. 2005 Sep;8(4):197-9.

23. Tunçez $A$, Altunkeser BB, Öztürk $B$ et al. Comparative effects of atorvastatin $80 \mathrm{mg}$ and rosuvastatin $40 \mathrm{mg}$ on the levels of serum endocan, chemerin, and galectin-3 in patients with acute myocardial infarction. Anatolian Journal of Cardiology. 2019;22(5):240.

24. Rosenson RS, Otvos JD, Hsia J. Effects of rosuvastatin and atorvastatin on LDL and HDL particle concentrations in patients with metabolic syndrome: a randomized, double-blind, controlled study. Diabetes care. 2009 Jun 1;32(6):1087-91.

25. Adams SP, Wright JM. Lipid lowering efficacy of rosuvastatin. Cochrane Database of Systematic Reviews. 2012(12).

26. Barry AR, Beach JE, Pearson GJ. Prevention and management of statin adverse effects: a practical approach for pharmacists. Canadian Pharmacists Journal/Revue des Pharmaciens du Canada. 2018 May;151(3):179-88. 